Primljen / Received: 10.6.2016. Ispravljen / Corrected: 4.10.2017.

Prihvaćen / Accepted: 11.12.2017. Dostupno online / Available online: 10.6.2018.

\section{Dissipation of mechanical energy over spillway through counter flow}

Authors:

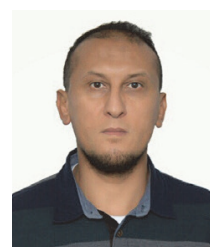

Amad.Deen Abdusalam Alghwail, MCE Lecturer at Elmergib University, Libya Union-Nikola Tesla University, Serbia civileng_amad@yahoo.com

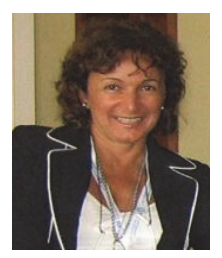

Prof. Svetlana Stevović, PhD. CE

University of Belgrade

Faculty of Mechanical Engineering

Innovation Center

sstevovic@mas.bg.ac.rs

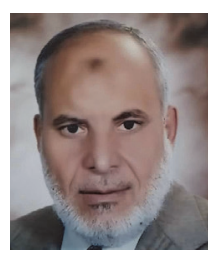

Prof. Mohammad A. Abourohiem, PhD. CE Alexandria University, Egypt Faculty of Civil Engineering Mrohim76@yahoo.com
Preliminary report

Amad.Deen Abdusalam Alghwail, Svetlana Stevović, Mohammad A. Abourohiem

\section{Dissipation of mechanical energy over spillway through counter flow}

A reversed flow in form of cross-jet serves for dissipation of the energy of flow after spillway. Parameters influencing characteristics of hydraulic jump are systematically investigated via a physical model. The obtained results reveal that the reversed flow can speed up the transition from supercritical to subcritical flow by creating a forced hydraulic jump and, consequently, by shortening the protection length needed to counter scouring problems downstream of the channel, since the length of hydraulic jump is reduced by $19 \%$. The efficiency of such energy dissipation methods can have a significant impact on the overall construction cost of hydraulic structures.

Key words:

energy dissipation, local scour, counter flow dissipater, hydraulic jump, stilling basin length

Prethodno priopćenje

Amad.Deen Abdusalam Alghwail, Svetlana Stevović, Mohammad A. Abourohiem

\section{Rasap mehaničke energije preljevnog mlaza pomoću suprotstavljenog toka}

Reverzni tok u formi poprečnog mlaza služi za disipaciju energija toka nakon preljeva. Parametri koji utječu na karakteristike vodnog skoka sustavno se istražuju pomoću fizikalnog modela. Dobiveni rezultati pokazuju da reverzni tok može ubrzati prelazak s burnoga na mirni tok ostvarivanjem prisilnog vodnog skoka, pa se time smanjuje dužina potrebne zaštite od podlokavanja u nizvodnom dijelu korita jer se dužina vodnog skoka smanjuje za $19 \%$. Djelotvornost takvih metoda za raspršivanje energije može znatno utjecati na ukupne troškove izvođenja hidrotehničkih građevina.

Ključne riječi:

disipacija energije, lokalno podlokavanje, protustrujni disipator, vodni skok, dužina slapišta preljeva

Vorherige Mitteilung

Amad.Deen Abdusalam Alghwail, Svetlana Stevović, Mohammad A. Abourohiem

\section{Zerfall der mechanischen Energie des Überfallstrahls mithilfe der Gegenströmung}

Die Rückwärtsströmung in Form eines Querstrahls dient der Dissipation der Energie nach dem Überlauf. Die Parameter, welche die Eigenschaften des Wechselsprungs beeinflussen, werden anhand eines physikalischen Modells systematisch untersucht. Die erhaltenen Ergebnisse zeigen, dass die Rückwärtsströmung den Übergang von einer reißenden in eine ruhige Strömung durch Realisierung eines erzwungenen Wechselsprungs beschleunigen kann, womit sich die Länge des erforderlichen Schutzes vor Unterhöhlung im stromabwärts gelegenen Teil des Beckens verringert, da sich die Länge des Wechselsprungs um 19\% verringert. Die Wirksamkeit solcher Methoden zur Energiestreuung kann sich wesentlich auf die Gesamtkosten der Ausführung von hydrotechnischen Objekten auswirken.

Schlüsselwörter:

Dissipation der Energie, lokale Unterhöhlung, entgegenwirkender Dissipator, Wechselsprung, Länge des Sturzbettes des Überlaufs 


\section{Introduction}

Dam spillways are commonly built in streams with alluvial bed materials (erodible materials) such as sand, clay and silt. A spillway is a means to prevent dam overtopping in the event of extreme weather conditions. It allows release of a vast amount of water from the reservoir over a short period of time, resulting in a very high velocity of discharge. This normally assumes the form of a highly turbulent supercritical flow in the spillway and in the zone immediately downstream of the spillway. The high velocity of flow leads to an increase in the shear stress at the riverbed level, and the stress becomes much higher compared to the situation without the structure. This results in a significant increase in sediment transport to the downstream of the structure. The channel bed becomes highly eroded, which is commonly known as local scour, as illustrated in Figure 1. Successive scouring can undermine spillway foundations which may result, in the worst case scenario, in the failure of the structure itself $[1,2]$. That is why such local scouring must be prevented.

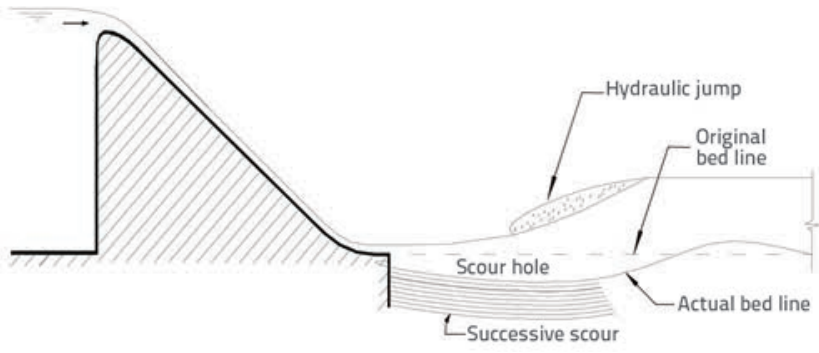

Figure 1. Scour process downstream of a spillway

To alleviate the scouring problem, the channel must be protected by lining downstream of the structure until the flow becomes subcritical, when the flow velocity is substantially lower. Under natural conditions, river flow is normally in a subcritical state and, when a supercritical flow occurs, it reverses back to subcritical at some point further downstream. The reversal from supercritical to subcritical flow always involves a hydraulic jump, as illustrated in Figure 1.

\subsection{Water energy dissipation methods and techniques}

The cost of channel protection is directly proportional to the distance between the spillway and the hydraulic jump zone. Two approaches can be used to move the hydraulic jump forward, thus reducing the distance. Raising the downstream flow depth can be achieved relatively easily, as in the case of a stilling basin.

Baffle blocks, end sill, positive and negative steps, splitter block and buckets, may be used as barriers or obstructions in the stilling basin to reduce the flow velocity and shorten the hydraulic jump length, resulting in better energy dissipation without increasing the water depth in the channel [3-5].
A good example is the stepped spillway. As water flows down the steps, turbulent mixing and diffusion can produce greater dissipation of energy compared to dissipation occurring on smooth spillways [6, 7].

\subsection{Energy dissipation by counter-flow}

At fundamental level, energy dissipation of a fluid flow relies on internal friction due to viscous effects and turbulent diffusion. The frictional head loss is directly proportional to velocity gradient, while diffusion depends on the intensity of the turbulence. Air entrainment enhances turbulent intensity, while a high velocity jet impacting on the stationary or low velocity liquid increases both the level of turbulence and velocity gradient as in the case of stepped spillways. Installing baffles in a stilling basin forces the flow to change direction abruptly, which generates a highly non-uniform flow, and an increased velocity gradient and head loss (commonly known as the local head loss). Turbulence also occurs when water flow hits obstructions. It is, therefore, highly important in the energy dissipation process that any method used must maximise turbulence and velocity gradient. This is best demonstrated by the counter flow approach.

The concept of energy dissipation by counter flow depends on collision between opposing flows. The collision of two opposing flows may happen in the air or within a stilling basin. Komora [8] suggested a technique that produces collision of jets in the air by installing three spreader blocks at the channel, resulting in significant reduction in the volume of the earth and concrete work for the spillway.

A splitter block having a V- shaped structure, installed on the stilling basin floor to divide the incoming flow into two parts, was designed by Vollmer and Khader [9]. It creates a heavy loss of water energy due to collision. Kao [10] carried out an experimental and theoretical analysis to study the effect of floor jet on the formation of hydraulic jump. The results show that hydraulic jump can be controlled by using a submerged cross-jet instead of solid chute blocks and baffle piers, and that the tailwater depth reduces and much energy is dissipated by reverse jet, compared to a free hydraulic jump.

\subsection{Issues associated with current energy- dissipation methods}

Cavitation is a common problem associated with energy dissipation solutions. Low pressure can be the result of flow separation at high velocity over the spillway steps or dissipaters like baffles in stilling basins. At outlets and spillways, it may occur on the lateral and rear faces of baffle blocks, sills and protuberances in stilling basins [11, 12]. Frizell, Renna and Matos [13] show that the formation of vapour-filled bubbles and cavities and their continuous collapse results in a considerable damage to numerous spillway parts and components of hydraulic structures around the world. 
In the stilling basin, bottom outlets may be subjected to abrasion due to formation of cavities in the high-flow velocity zones [12]. A stilling basin with baffle blocks is not recommended when the velocity of flow is more than $20-30 \mathrm{~m} / \mathrm{s}$ due to the risk of erosion and cavitation damage to the structure [14].

On the stepped spillways, a skimming flow forms a highly intense shear layer along the line connecting successive step tips (also called the pseudo bottom). The flow structure within this shear layer supports formation of cavitation along secondary flow features [15-17]. Pfister et al [18, 19] investigated measures to prevent or limit cavitation damage associated with stepped spillways. Two aerators were located at the vertical face of the first step to provide air at the bottom of the chute, and their effectiveness was examined. There were noticeable differences immediately downstream of the aerator, but these were not obvious in the far-downstream reaches of the chute. Boes and Hager [20] reported critical velocity for cavitation inception in the flow, prior to air entrainment, of approximately $20 \mathrm{~m} / \mathrm{s}$. They recommended limiting design specific discharges to about $25 \mathrm{~m}^{2} / \mathrm{s}$. Amador et al [21] recommended mean velocity of $15 \mathrm{~m} / \mathrm{s}$ at the inception point based on the $0.1 \%$ probability of extreme negative pressures measured near the edge of the vertical step faces on a steeply sloping chute. However, the use of specific discharge and velocity as a design recommendation for spillways to prevent cavitation occurrence may be misguiding without knowing when and whether the cavitation will form.

The use of spreader or splitter blocks in the counter flow techniques as a means to deflect a part of the flow into the air, or to direct flows against each other, may cause cavities due to separation of flowing water when colliding with the blocks.

\subsection{Collision process}

A jet of water hitting a stationary object or another body of water is a form of inelastic collision. The momentum is conserved but the kinetic energy of the flowing water is to a large extend converted into other forms of energy (heat, acoustical energy, and potential energy) due to the work performed to deform the objects [22]. Varying levels of kinetic energy remain, depending on the setup of the jet flow. Having two opposing flows of water colliding with one another (the counterflow) has the effect of increasing the impact, leading to conversion of an increased proportion of kinetic energy into heat. At the same time, the level of turbulence rises along with the magnitude of the velocity gradient, which results in an increased head loss in the flowing water. In essence, water particles deformation and friction during flow collision and through severe turbulentflow zone due to formation of hydraulic jump, will remove a part of mechanical energy from the water particles by way of lowering the average relative velocities of colliding particles [23].

\section{Methods}

As stated above, there is always a need for new and/or improved energy dissipation methods. The current study explores the counter-flow concept as an energy dissipation method through systematic examination of water flow. The basic principle of counter-flow is to split the flow into two flows and to direct these flows against one another. The energy dissipation is experimentally examined under simple flow conditions. The fundamental energy, momentum, and continuity equations, are applied to predict parameters such as the discharge through slot, relative energy loss, and the condition of perfect hydraulic jump. It should be possible to estimate where the hydraulic jump takes place, and what is the distance from the toe of the structure. As the stilling basin is normally an integral part of the overall structure, this distance is referred to as the floor length. The greater the floor length, the more construction material is needed and, therefore, the greater the cost.

The actual process of energy dissipation, involving complex structures and impacts of flow, is very complicated and requires physical modelling under controlled laboratory conditions so that a proper insight into the flow behaviour can be gained. A number of physical models of different design have been constructed to create various counter-flow configurations. The effect of counter-flow width, location, and angle of slot, is experimentally studied to obtain proper design values of the extent of counter-flow. All models were tested under an identical set of flow conditions, and a series of key flow parameters was measured. Flow characteristics and energy dissipation efficiency were directly evaluated by means of such measurements. It was also possible to quantify different stages of energy dissipation as water travelled from the upstream to downstream of the spillway. Unlike previous related studies where the focus was on the resulting energy dissipation, the current study provides fundamental understanding of the process through measurements of a range of key parameters involved in the process. Therefore, the effectiveness of the energy dissipation methods is assessed from an energy perspective as well as from the point of view of economics.

\section{Analytical procedures}

In this section, the main purpose is to predict theoretical equations including the parameters involved in the problem. These equations might be used for estimating the energy loss and characteristics of a forced hydraulic jump, in the case of cross-jet (counter flow). In addition to the discharge of the cross-jet (slot), the contracted depth at the toe of the ogee weir spillway had to be primarily established to get the energy loss equations for this case. The essential equations of flow energy, momentum and continuity were used to develop theoretical solutions. The back face of an ogee weir spillway acts as an inclined surface. Therefore, the reversed cross-jet dissipater was applied to dissipate the energy of flow to the downstream of the spillway. 


\subsection{Determination of the contracted depth downstream of an ogee weir spillway}

The contracted depth greatly influences flow conditions to the downstream of the spillway. This involves the Froude number, flow velocity, hydraulic jump characteristics, and measures that are required for any energy dissipation design. The depth of flow at the toe is usually obtained using graphs for certain velocity coefficient values. Appropriate procedures are used to solve energy equations using trial and error techniques for the assumed values of the coefficient that causes difficulties. The energy equation is also used in other techniques but the energy loss is not taken into account (velocity coefficient, $C_{v}=0$ ), which leads to great mistakes in the determination of contracted depth. The procedure for the contracted depth determination, as presented by Abourohim [24], is illustrated in this study. As shown in Figure 2, the contracted depth $y_{c}$ can be obtained by applying the energy equation (Bernoulli's equation) between the approaching section 1-1 and the contracted section 2-2 at which the contraction of flow occurs. For more accurate estimation of the contracted depth, the energy loss $h_{L 1-2}$ between the two mentioned sections should be considered.

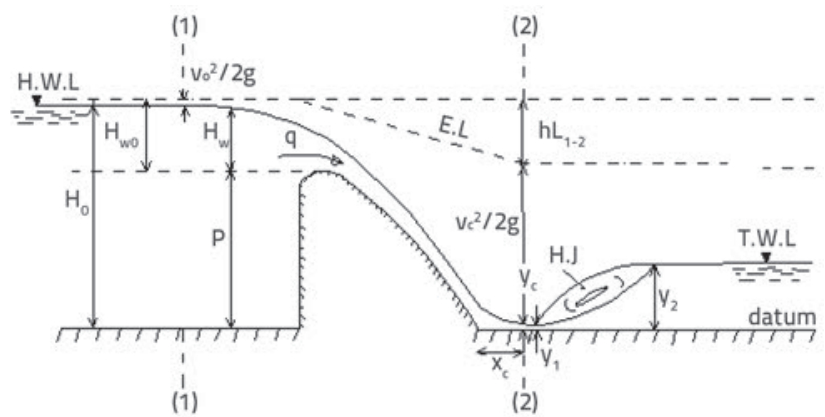

Figure 2. Determination of contracted depth

Taking the downstream bed as a datum, and equating the specific energy equations at sections $1-1$ and $2-2$, we get:

$H_{0}=y_{c}+\frac{\alpha_{2} v_{c}^{2}}{2 g}+h_{12}$

The energy $h_{L_{-2}}$ on spillway surface can be expressed as: $h_{L_{1-2}}=\xi$ $\left(v_{c}{ }^{2} / 2 g\right)$ where $\xi$ is the head loss coefficient. Substituting for $h_{L_{1-2}}$ in Eqn. (1) yields:

$H_{0}=y_{c}+\frac{v_{c}^{2}}{2 g}(1.0+\xi)$

where $H_{0}=p+H_{W_{0}}, H_{W_{0}}=H_{W}+\frac{a_{1} v_{0}^{2}}{2 g}$ and $v_{0}=\frac{q}{p+H_{W}}$. It follows

$H_{W_{0}}=H_{W}+\frac{\alpha_{1} q^{2}}{2 g\left(p+H_{W}\right)^{2}}$.

Where $H_{w}$ is the head over the weir crest, $p$ is the crest height $\theta$ is the discharge per unit width, $\theta=Q_{w} / B, v_{0}$ is the flow velocity at section $1-1, v_{c}$ is the flow velocity at section $2-2, \alpha_{1}$ and $\alpha_{2}$ sare correction factors for kinetic energy, and $B$ is the width of the channel.
Considering $\alpha_{1}=\alpha_{2}=1,0$, Eqn. (2) becomes:

$H_{0}=y_{c}+\frac{v_{2}^{2}}{2 g}(1.0+\xi)$

from which the actual velocity $v_{c}=v_{\text {act }}$ is given as: $v_{\text {act }}=1 / \sqrt{1+\xi} \sqrt{2 g H_{0}}$. Neglecting $h_{\mathrm{L} 1-2}$ the theoretical velocity $v_{c}=$ $v_{a c t}$ is written as: $v_{t h}=\sqrt{2 g\left(H_{0}\right)}$.

Since the velocity coefficient $C_{v}$ is defined as the ratio between the actual and theoretical velocities $C_{v}=v_{\text {act }} / v_{\text {th }}$, then, $C_{v}=1 / \sqrt{1.0+\xi}$.

Substituting for $C_{v}$ in Eqn. (3) gives $H_{0}=y_{c}+\frac{v_{c}{ }^{2}}{2 g C_{v}{ }^{2}}$.

Substituting for $v_{2}=q / y_{c}$ gives $H_{0}=y_{c}+\frac{q_{2}{ }^{2}}{2 g y^{2}{C_{v}}^{2}}$.

For rectangular section, the critical depth is given as:

$y_{c_{r}}=\sqrt[3]{\frac{q^{2}}{g}}$ or $q^{2}=\frac{y_{c_{r}}{ }^{3}}{g} \cdot y_{c}$ substituting for yields gives

$y_{c}{ }^{3} H_{0} y^{2}+\frac{y_{c_{r}}{ }^{3}}{2 C_{v}{ }^{2}}=0$

Put $m=-H_{0}$ and $n=y_{c}{ }^{3} / 2 C_{v}{ }^{2}$ in Eqn. (4) gives

$y_{c}^{3}+m y_{c}^{2}+n=0$

Eqn. (5) is a cubic equation for $y_{c}$. Using Cardano's Method, the three roots of the equation are found as follows: First, we eliminate the term containing $y_{c}^{2}$ by putting $y_{c}-\frac{m}{3}$ instead of $y_{c}$ in Eqn. (5). Therefore:

$\left[y_{c} \frac{m}{3}\right]^{3}+m\left[y_{c} \frac{m}{3}\right]^{2}+n=0$

$y_{c}^{3}-3 y_{c}^{2} \frac{m}{3}+3 y_{c} \frac{m^{2}}{9}-\frac{m^{3}}{27}+m\left[y_{c}^{2}-\frac{2 m y_{c}}{3}+\frac{m^{2}}{9}\right]+n=0$,

$y_{c}^{3}-3\left[\frac{1}{9} m^{2}\right] y_{c}+\frac{2}{27} m^{3}+n=0$.

If $f=\frac{2}{27} m^{3}+n$ id $=\frac{-1}{9} m^{2}$, the above equation becomes:

$y_{c}^{3}+3 d y_{c}+f=0$

Using trigonometric solution for a $3^{\text {rd }}$ degree equation and substituting for $y_{c}=K \cos \lambda$ in Eqn. (6), one gets, $(K \cos \lambda)^{3}+3 d K \cos \lambda+f=0$. Multiplying by $4 / k^{3}$ yields, $4 \cos ^{3} \lambda+\frac{3 \times 4}{K^{2}} d \cos \lambda+f \frac{4}{K^{3}}=0$ or $4 \cos ^{3} \lambda-3\left[\frac{-4 d}{K^{2}}\right] \cos \lambda=-f \frac{4}{K^{3}}$, from
which:

$K^{3} \cos ^{3} \lambda+3 d K \cos \lambda+f=0$

Knowing that $\cos 3 \lambda=4-\cos ^{3} \lambda-3 \cos \lambda$

and assuming that $\frac{-4 d}{K^{2}}=1 \rightarrow K^{2}=-4 d=-4 \cdot \frac{-1}{9} m^{2}=\frac{4 m^{2}}{9}$,

then $K=\frac{2 m}{3}, \cos 3 \lambda=-f \frac{4}{K^{3}}, 3 \lambda=(\pi-\gamma)+2 \pi k \mathrm{i} \lambda=\left[\frac{\pi-\gamma}{3}\right]+\frac{2 \pi k}{3}$. 
Since we have a cubic equation, let $\mathrm{k}=0,1,2$, respectively

$\underline{k}=0$

$y_{c}=K \cos \left[\frac{\pi}{3}-\frac{\gamma}{3}\right]-\frac{m}{3}=\frac{2 m}{3} \cos \left[\frac{\pi}{3}-\frac{\gamma}{3}\right]-\frac{m}{3}=\frac{m}{3}\left[-1+2 \cos \left(\frac{\pi}{3}-\frac{\gamma}{3}\right)\right]$

Substituting for $m=-H_{0}$ we get;

$\mathrm{y}_{\mathrm{c}}=\frac{\mathrm{H}_{0}}{3}\left[1-2 \cos \left(\frac{\mathrm{Y}}{3}-\frac{\pi}{3}\right)\right]$

$\underline{k=1}$

$y_{c}=K \cos \left[\pi-\frac{\gamma}{3}\right]-\frac{m}{3},=K \frac{2 m}{3} \cos \left[\pi-\frac{\gamma}{3}\right]-\frac{m}{3},=-\frac{m}{3}\left[1-2 \cos \left(\pi-\frac{\gamma}{3}\right)\right]$

then

$y_{c}=\frac{H_{0}}{3}\left[1+2 \cos \left(\frac{\gamma}{3}\right)\right]$

$\underline{k}=2$

$y=K \cos \left[2 \pi-\frac{\pi}{3}-\frac{\gamma}{3}\right]-\frac{m}{3},=K \frac{2 m}{3} \cos \left[\frac{\gamma}{3}+\frac{\pi}{3}\right]-\frac{m}{3},=-\frac{m}{3}\left[1-2 \cos \left(\pi-\frac{\gamma}{3}\right)\right]$

then

$y_{c}=\frac{H_{0}}{3}\left[1-2 \cos \left(\frac{\gamma}{3}+\frac{\pi}{3}\right)\right]$

Equation (8) gives negative values for $y_{c^{\prime}}$ while Eqns. (9) and (10) give values of $y_{1}>y_{c}$ and $y_{1}<y_{c}$ respectively. The depth $y_{c}$ in Eqn. (9) represents the contracted depth in the submerged flow condition, while $y$ in Eqn. (10) is the contracted depth of the free flow condition.

Considering the free flow condition, the flow depth at the spillway toe $y_{c}$ can be calculated by using Eqn. (10),

where $\cos \gamma=f \frac{4}{K^{3}}=\left(\frac{-2}{27} H_{0}{ }^{3}+\frac{y_{C_{r}}{ }^{3}}{2 C_{v}{ }^{2}}\right) \times \frac{4}{\left(-2 H_{0} / 3\right)^{3}}$ or $\cos \gamma=\left(1-\frac{4 \times 27 y_{c_{r}}{ }^{3}}{2 C_{v}{ }^{2} \cdot 8 H_{0}{ }^{3}}\right)$,

and, finally, $\cos Y=\left(1-\frac{6.75}{C_{v}{ }^{2}}\left(\frac{y_{c_{r}}}{H_{0}}\right)^{3}\right)$.

By using the experimental data, an empirical formula presented by Abourohim [25] can be used to estimate the velocity coefficient $C_{v}$ for values $0.05<H_{w} / p \leq 1.0$ in the following form:

$C_{v}=1+0,07 \ln H_{w} / p$

where: $H_{w}$ is the head on the weir crest and $p$ is the crest height.

\subsection{Determination of cross-jet discharge}

The issuing jet is considered a flow through a submerged orifice since the thickness of slot wall exceeds the slot width $b$ by three times. Such a submerged orifice works under a net head $h_{s}$ equal to the difference between the headwater depth $H$ and the height of water immediately above the slot opening. Considering
Figure 3, the following is obtained by applying energy equation at section $0-0$ and $\mathrm{S}-\mathrm{S}$ :

$v_{s}=C_{v_{s}}\left[2 g\left(H-y_{1}-x \tan \alpha\right)\right]^{0.5}$

where $v_{s}$ and $C_{v s}$ are the velocity and the velocity coefficient for the discharging jet issuing from the slot.

Since the slot is considered as a submerged mouthpiece, the coefficient of contraction of the mouthpiece $C_{c}$ is assumed to be unity. Consequently, both velocity and discharge coefficients of slot $C_{v s}$ and $C_{d s^{\prime}}$ are the same.

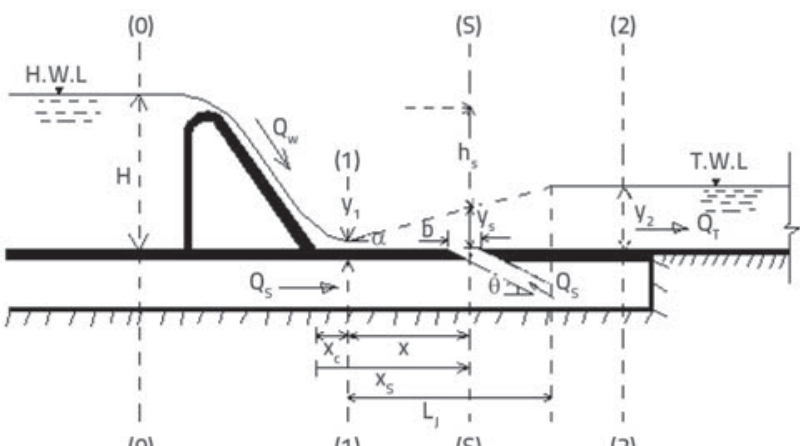

(0)

(1)

(S)

(2)

Figure 3. Determination of cross-jet discharge

Also, with regard to Figure $3 \tan \alpha=\left(y_{2}-y_{1}\right) / L_{j}$ and/or $\tan \alpha=$ $\left(y_{2}-y_{1}\right) / x$, from which $y_{\mathrm{s}}=y_{1}+x \tan \alpha$, then Eqn. (12) can be rearranged as follows:

$v_{s}=C_{d_{s}} \sqrt{2 g y_{2}}\left[\frac{H}{y_{2}}-\frac{y_{1}}{y_{2}}-\frac{x}{L_{J}}\left(1-\frac{y_{1}}{y_{2}}\right)\right]^{0.5}$

where $x$ is the horizontal distance between the centre of the slot and the contracted section, i.e. $x=x_{s}-x_{c^{\prime}}$ where $x_{s}$ and $x_{c}$ are the distance to position of the slot and the contracted section measured from the weir toe, respectively. Considering that the width of the flow at section S-S is the same as the slot width, the continuity equation gives $Q_{s}=b B v_{s^{\prime}}$ where $B$ is the width of the channel and $b$ is the width of the slot. Substituting for $v_{s}$ from Eqn. (13), the slot discharge is given as:

$Q_{S}=\beta_{1} B b \sqrt{2 g y_{2}}$

where $\beta_{1}=C_{d_{s}}\left[\frac{H}{y_{2}}-\frac{y_{1}}{y_{2}}-\frac{x}{L_{J}}\left(1-\frac{y_{1}}{y_{2}}\right)\right]^{0.5}$, and $C_{d s}$, s the coefficient of discharge of the slot.

\subsection{Energy dissipated by forced jump}

The energy dissipation can be found by evaluating the difference between the total energy before the jump and the total energy after it. This can be written as follows:

$E_{L}=\left(y_{1}+\frac{v_{1}^{2}}{2 g}\right)-\left(y_{2}+\frac{v_{2}^{2}}{2 g}\right)$

where $E_{L}=$ the energy loss per unit weight due to hydraulic jump. 
According to the principle of conservation of mass and for a constant density, $q_{2}=q_{1}-q_{s^{\prime}}$ substitution into Eqn. (15), where $q_{1}=v_{1} y_{1}, q_{s}=\beta_{2} b \sqrt{2 g y_{1}}$ (from Eqn. 14) and $\delta_{2}=b / y_{\text {, we get: }}$

$\frac{E_{L}}{y_{1}}=\left(1+\frac{F_{1}^{2}}{2}\right)-\psi-\frac{1}{\psi^{2}}\left[\frac{F_{1}^{2}}{2}+\sqrt{2} F_{1} \beta_{2} \delta_{2}+\beta_{2}^{2} \delta_{2}^{2}\right]$

putting $\delta_{2}=0$ Eqn. (16) may be reduced to the classical equation that is used to calculate the energy loss for a simple free hydraulic jump.

\section{Experimental study}

The present problem is handled experimentally, under an identical set of flow conditions. All models are tested and series of key parameters are measured. Some coefficients are determined using experimental data. The flow characteristics and the energy dissipation efficiency are evaluated directly to obtain proper design values of slot dimensions: width, angle and location. Therefore, the problem is treated experimentally on a physical model of a spillway having an inclined surface. The ogee weir spillway is chosen for this purpose, since its back face is an inclined surface.

\subsection{Experimental set-up and arrangements}

The experiments were conducted at the Laboratory of Fluid Mechanics, Faculty of Engineering, Elmergib University, see Figure 4. Experimental work was conducted using experimental set-up specially prepared to study the effect of main crossjet parameters on the characteristics of the formed hydraulic jump considering two cases, free perfect jump (without cross jet) and forced perfect jump (with cross jet). The testing flume comprised a rectangular channel section $5.0 \mathrm{~m}$ in length, $7.6 \mathrm{~cm}$ in width, and $25 \mathrm{~cm}$ in height (See Appendix 1).

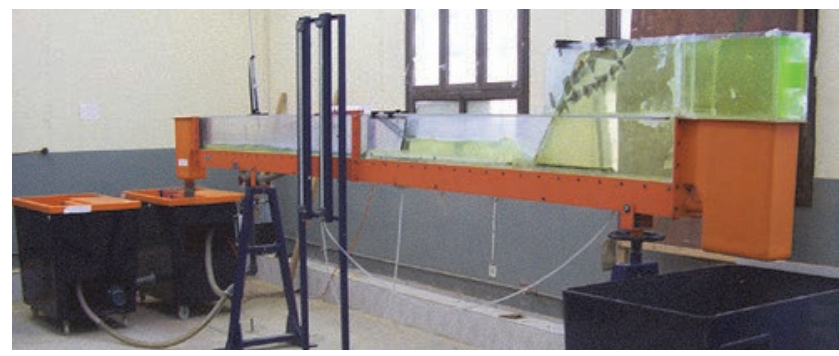

Figure 4. Experimental set up components

\subsubsection{Details of dissipater model}

The inclined surface of the spillway is represented by an inclined plate joining the crest of the ogee weir to the testing flume bottom. It is $10 \mathrm{~mm}$ thick, $1.0 \mathrm{~V}: 0.7 \mathrm{H}$ in slope, and $43.5 \mathrm{~cm}$ in height $p_{t}$ as shown in Figure 5. The slope of the back face of the spillway was chosen according to previous studies [25-30]. Such a slope prevents separation of flow from the inclined surface. The slot was formed through a Perspex sheet $15 \mathrm{~mm}$ in thickness, representing the structure floor. The slot angle, width, and position, were selected according to the values listed in Table 1. It should be noted that the slot angle provides the direction of the cross jet flow with respect to horizontal direction, as shown in Figure 5.

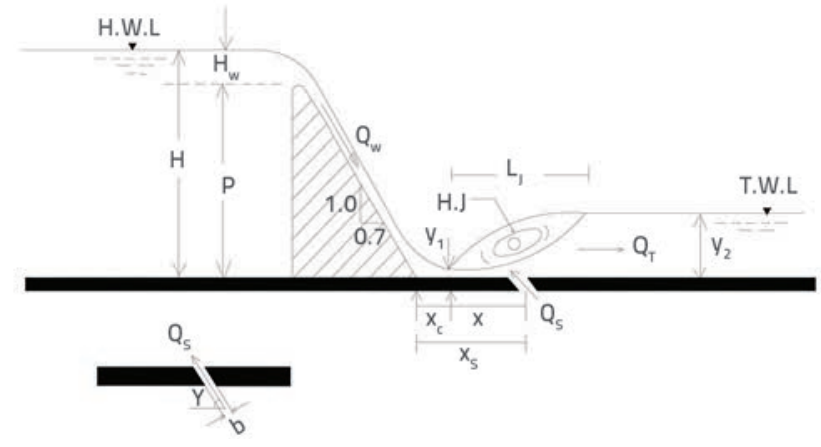

Figure 5. Details of dissipater model

\subsubsection{Measuring devices}

The circulated flow was measured with a calibrated sharpedged rectangular weir. The obtained discharge equation may be expressed as:

$Q=0.27485 h^{1.578}[\mathrm{l} / \mathrm{s}]$

\subsection{Experimental procedure}

\subsubsection{Case of perfect free jump}

Constant values of the discharge passing over the spillway, i.e. $Q_{w}=0.5,1,1.5,2$, and $2.5 \mathrm{l} / \mathrm{s}$, correspond to headwater depths $H=45.7,46.98,48.05,48.98$, and $49.85 \mathrm{~cm}$, respectively. The contracted section is assigned for every discharge, and the contracted depth $y_{c}$ and its distance from the weir toe $x_{c}$ is measured. The position of the hydraulic jump is adjusted using the tail gate, so that the front of the jump is immediately at the contracted section enabling a perfect jump, where $y_{1}=y_{i}$. The tailwater depth and length of the jump $L$, are also measured.

\subsubsection{Case of perfect forced jump}

Considering constant values of both the slot width $b=0.15 \mathrm{~cm}$ and inclination angle $\theta=15^{\circ}$, the slot location is fixed at the distances of $x_{s}=5,10,15,20,25$ and $30 \mathrm{~cm}$. Considering $x_{s}=5$ $\mathrm{cm}$, the pump is turned on and the control valve is adjusted to give the same headwater depth $H$ used in the case of the free jump. In this case, the discharge passing over the weir spillway $Q_{w}$ remains constant as considered in the case of the free jump. Using the tail gate, the tailwater depth is gradually reduced until the jump front is located immediately at the contracted section. Here, the initial depth values $y_{1}$ or $y_{c}$ are still at the same value established in the case of the free jump since $Q_{w}$ is not changed. The tailwater depth $y_{2}$ and the length of forced jump $L$, are then measured. The head on the rectangular weir is measured and the total discharge $Q_{T}$ is then estimated using Eqn. (17). 
The discharge issuing from the slot $Q_{S}$ is then found since $Q_{S}$ $=Q_{T}-Q_{w}$. The above steps are repeated for other values of $H$ while also considering other slot dimension and location values (fixing one slot dimension value and changing the others), as illustrated in the Table 1. It should be noticed that a sufficient time was allowed to satisfy a steady state condition of flow before recording the measured values.

Table 1. Tested values of considered parameters

\begin{tabular}{|l|c|c|c|}
\hline \multirow{2}{*}{ Variable parameters } & \multicolumn{3}{|c|}{ Fixed parameters } \\
\cline { 2 - 5 } & $\boldsymbol{X}_{s}$ & $\theta$ & $\boldsymbol{b}$ \\
\hline Distance of slot location $[\mathrm{cm}] \cdot \mathrm{X}_{\mathrm{s}}=5.10 .15 .20 .25 .30$ & - & $15^{0}$ & 0.15 \\
\hline Inclination angle of slot $\left[{ }^{\circ}\right] \cdot \theta=15.30 .45 .60 .75 .90$ & 15 & - & 0.15 \\
\hline Width of slot $[\mathrm{cm}] . b=0.15 \cdot 0.20 .0 .25 .0 .30$ & 15 & $45^{\circ}$ & - \\
\hline
\end{tabular}

\subsubsection{Main parameters involved in current problem}

The formed hydraulic jump can generally be described by: the conjugate depth ratio $\left(y_{2} / y_{1}\right)$, the relative length of jump $\left(L / y_{1}\right)$, and the relative energy dissipated through the jump $\left(E_{L} / y_{1}\right)$. Referring to Figure 5, the parameters affecting hydraulic jump characteristics: $\left(y_{2} / y_{1}\right),\left(L / y_{1}\right)$, and $\left(E_{L} / y_{1}\right)$, may be grouped as follows:

1. Boundary parameter: The inclined surface height $p=43.5$ $\mathrm{cm}$, the width of the tailwater channel $B=7.6 \mathrm{~cm}$, the distance of slot position $x_{s^{\prime \prime}}$, the width of slot $b$, and the inclination angle of slot $\theta$.

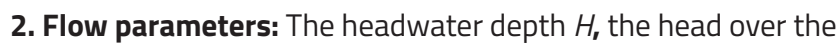
weir crest $H_{w^{\prime}}$ the initial depth of jump $y_{1}=y_{c^{\prime}}$ the depth of flow downstream of the jump $y_{2}$, the mean velocity at the contracted section $v_{1}$, the discharge passing over the weir $Q_{w}$, and the discharge passing through the slot $Q_{S}$.

Excluding the parameters, which were kept constant, and using the dimensional analysis, the following dimensionless relation for the conjugate depth $\left(y_{2} / y_{1}\right)$ can be written as follows:

$\frac{y_{2}}{y_{1}}=f\left(\frac{x_{S}}{y_{1}}, \theta, \frac{b}{y_{1}}, F_{1}, R_{N}, \frac{Q_{W}}{Q_{S}}\right)$

The effect of viscosity may be neglected due to the high values of Reynolds number involved in the study [31, 32]. Thus, the above relation can be expressed as:

$\frac{y_{2}}{y_{1}}=f_{1}\left(\frac{x_{S}}{y_{1}}, \theta, \frac{b}{y_{1}}, F_{1}, \frac{Q_{W}}{Q_{S}}\right)$

The situation is similar for the relative length of jump and relative energy dissipation.

$\frac{L_{J}}{y_{1}}=f_{2}\left(\frac{x_{S}}{y_{1}}, \theta, \frac{b}{y_{1}}, F_{1}, \frac{Q_{W}}{Q_{S}}\right)$

$\frac{E_{L}}{y_{1}}=f_{3}\left(\frac{x_{S}}{y_{1}}, \theta, \frac{b}{y_{1}}, F_{1}, \frac{Q_{W}}{Q_{S}}\right)$
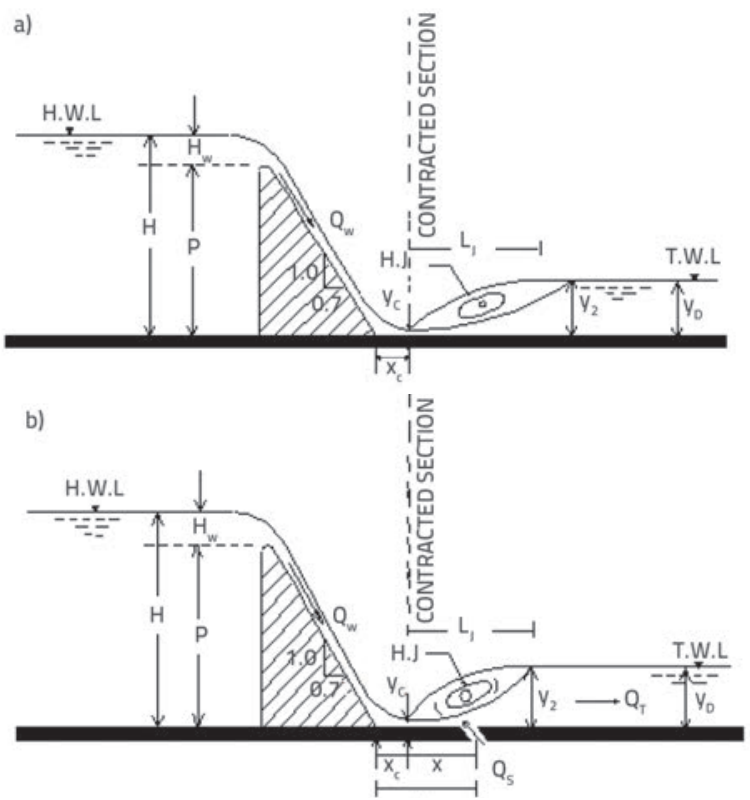

Figure 6. Definition sketch for: a) free perfect jump; b) forced perfect jump

\section{Analysis of results}

The main parameters involved in the current problem are: the distance of slot location $x_{s^{\prime}}$ the angle of slot to the horizontal $\theta$, the width of slot $b$, and the Froude number of the incoming (supercritical) flow $F_{1}$. Different values of $x_{s^{\prime}} \theta, b$ and $F_{1^{\prime}}$ were experimentally investigated as indicated in Table 1 . The proper value of the distance $x_{s^{\prime}}$ the angle $\theta$ or the width $b$ of slot gives minimum values of both relative length of jump $L / y_{1}$ and conjugate depths ratio $y_{2} / y_{1}$, and maximum values of the relative loss of energy $E_{L} / y_{1}$

The case of free jump in which the cross jet does not exist, was also investigated as a reference data, in order to indicate the effect of the above parameters on the hydraulic jump characteristics, and to compare results obtained from the case of forced jump formed due to the cross jet flow.

The comparison is based on the obtained results, considering the case of the perfect hydraulic jump, either free or forced, as shown in Figure 6.

The case in which a perfect jump is formed occurs when the front of the jump is just at the contracted section, located at the distance $x_{c}$ from the toe of the weir. In this case, the initial depth of jump $y_{1}$ equals the contracted depth $y_{c^{\prime}}$ while the second depth of jump $y_{2}$ equals the tailwater depth $y_{D}$.

Referring to Figure 6, cases of perfect free jump and perfect forced jump have the same conditions of flow upstream the contracted section, wherever $x_{s}>x_{c}$ t the head water depth $H$, the head over the weir crest $H_{w}$ and discharge passing over the weir $Q_{w}$

Downstream of the contracted section, the above cases have different conditions: the total discharge $Q_{T}$ and the tailwater depth $y_{2}$. In case of free jump, where $Q_{S}=0$, the total discharge 
$Q_{T}$ equals the weir discharge $Q_{W}$ or $Q_{T}=Q_{W}$ while $Q_{T}=Q_{W}+Q_{S}$ in case of forced jump, where $Q_{S}$ is the discharge passing through the slot. The analysis of results includes the following items:

- characteristics of perfect free jump

- effect of considered parameters on the perfect forced jump characteristics

- effect of the considered parameters on the drowned jump

- effect of the considered parameters on the discharge characteristics of the slot.

\subsection{Characteristics of perfect free jump}

Five runs having five values of the discharge passing over the weir. Tables 2 and 3 summarize the measured and calculated data, describing the characteristics of the free jump condition.

Measured initial depth values $y_{1}\left(y_{1}=y_{c}\right)$ are checked using derived Eqn. (10) and compared with calculated ones. As expected, a maximum deviation amounts to approximately $6 \%$. As for the conjugate depths ratio $\left(y_{2} / y_{1}\right)$, the measured values are always smaller than the ones obtained using the Belenger's formula, Eqn. (22), resulting in a maximum deviation of approximately $8 \%$.

$\psi=\frac{y_{2}}{y_{1}}=\frac{1}{2}\left(\sqrt{1+8 F_{1}^{2}}-1\right)$

The values of the conjugate depths ratio $\left(y_{2} / y_{1}\right)$ are plotted versus Froude number values $F_{1}$ as shown in Figure $7 a$, resulting in a linear relationship.

The relative length of jump $L / y_{1}=f\left(F_{1}\right)$ was established experimentally. Therefore, values $L / y_{1}$ were plotted against Froude number values, as given in Figure $7 \mathrm{~b}$. Using the regression analysis, a curve fitting equation for the jump length is obtained as:

$L_{j}=y_{1}\left(5.3142 F_{1}+7.5166\right)$

It was established that the measured results are very close to the ones calculated using the mentioned equation. Table 4 shows comparison between the measured and calculated values of $y_{1}\left(y_{1}=y_{c}\right),\left(y_{2} / y_{1}\right)$ and $L_{ر}$ for the perfect free jump.

Table 2. Measured data for perfect free jump

\begin{tabular}{|c|c|c|c|c|c|c|c|c|}
\hline $\boldsymbol{H}[\mathrm{cm}]$ & $\boldsymbol{Q}_{w}=\boldsymbol{Q}_{\boldsymbol{T}}\left[\mathrm{cm}^{3} / \mathrm{s}\right]$ & $\boldsymbol{H}_{w}[\mathrm{~cm}]$ & $\boldsymbol{x}_{\boldsymbol{c}}[\mathrm{cm}]$ & $\boldsymbol{L}_{\boldsymbol{j}}[\mathrm{cm}]$ & $\boldsymbol{y}_{\mathbf{1}}[\mathrm{cm}]$ & $\boldsymbol{y}_{2}[\mathrm{~cm}]$ & $\boldsymbol{F}_{\mathbf{1}}{ }^{1}$ & $\boldsymbol{F}_{\mathbf{2}}$ \\
\hline 45.70 & 500 & 2.20 & 3.00 & 23.00 & 0.29 & 5.00 & 13.45 & 0.19 \\
\hline 46.98 & 1000 & 3.48 & 5.32 & 35.00 & 0.50 & 7.50 & 11.88 & 0.20 \\
\hline 48.05 & 1500 & 4.55 & 8.25 & 45.00 & 0.73 & 9.60 & 10.10 & 0.21 \\
\hline 48.98 & 2000 & 5.48 & 11.00 & 53.00 & 0.94 & 11.25 & 9.22 & 0.22 \\
\hline 49.85 & 2500 & 6.35 & 13.50 & 61.00 & 1.13 & 12.75 & 8.74 & 0.23 \\
\hline
\end{tabular}

${ }^{1}$ Froude number ranges from 8.74 to 13.45 . In this range, the jump is well established, the roller and jump action is fully developed to cause appreciable energy loss. However, the water surface downstream of the jump is rough and wavy.

Table 3. Calculated data for perfect free jump

\begin{tabular}{|c|c|c|c|c|c|c|c|}
\hline $\boldsymbol{v}_{1}[\mathrm{~cm} / \mathrm{s}]$ & $\mathbf{v}_{2}[\mathrm{~cm} / \mathrm{s}]$ & $y_{2} / y_{1}$ & $L_{J} / y_{1}$ & $\boldsymbol{E}_{1}[\mathrm{~cm}]$ & $\boldsymbol{E}_{2}[\mathrm{~cm}]$ & $\boldsymbol{E}_{L}[\mathrm{~cm}]$ & $E_{L} / y_{1}$ \\
\hline 226.86 & 13.16 & 17.24 & 79.31 & 26.52 & 5.09 & 21.43 & 73.91 \\
\hline 263.16 & 17.54 & 15.00 & 70.00 & 35.80 & 7.66 & 28.14 & 56.28 \\
\hline 270.37 & 20.56 & 13.15 & 61.64 & 37.99 & 9.82 & 28.17 & 38.59 \\
\hline 279.96 & 23.39 & 11.97 & 56.38 & 40.89 & 11.53 & 29.36 & 31.23 \\
\hline 291.10 & 25.80 & 11.28 & 53.98 & 44.32 & 13.09 & 31.23 & 27.64 \\
\hline
\end{tabular}

a)

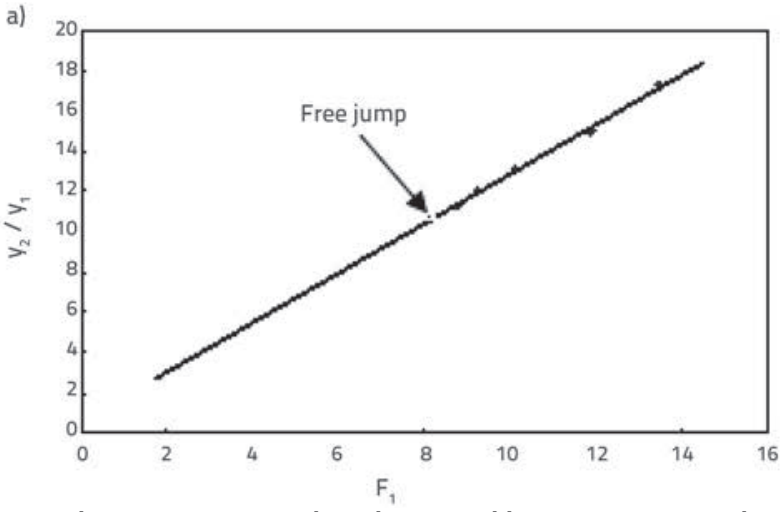

b)

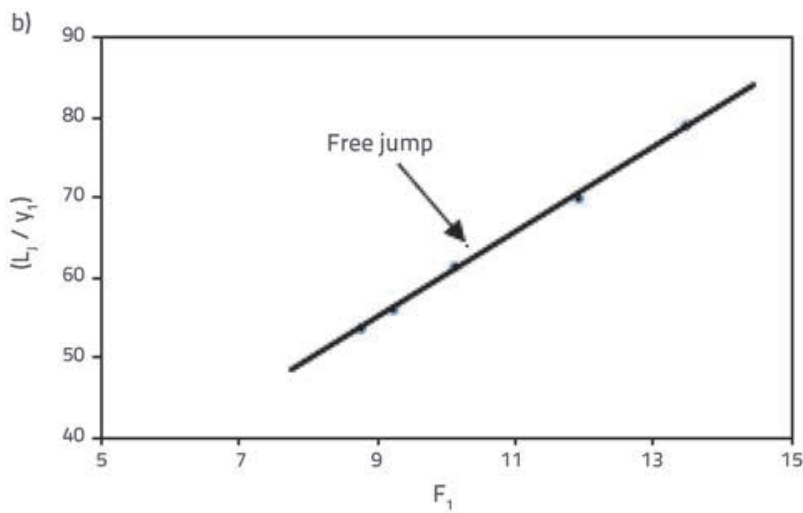

Figure 7. a) Relation between $\left(y_{2} / y_{1}\right)$ and $F_{1} ;$ b) ) Relation between $\left(L / y_{1}\right)$ and $F_{1}$ 
Table 4. Comparison between measured and calculated values of $y_{1}\left(y_{1}=y_{c}\right),\left(y_{2} / y_{1}\right)$ and $L_{1}$ for perfect free jump

\begin{tabular}{|c|c|c|c|c|c|c|c|}
\hline \multirow{2}{*}{$y_{2}[\mathrm{~cm}]$} & $y_{1}[\mathrm{~cm}]$ & $y_{1}{ }^{1}[\mathrm{~cm}]$ & $y_{2} / y_{1}$ & $y_{2} / y_{1}^{2}$ & $L_{,}[\mathrm{cm}]$ & $L_{1}^{3}[\mathrm{~cm}]$ & $y_{1}[\mathrm{~cm}]$ \\
\hline & Izmjereno & Izračunano & Izmjereno & Izračunano & Izmjereno & Izračunano & Izmjereno \\
\hline 5.00 & 0.29 & 0.28 & 17.24 & 18.53 & 23.00 & 22.91 & 5.00 \\
\hline 7.50 & 0.50 & 0.53 & 15.00 & 16.31 & 35.00 & 35.33 & 7.50 \\
\hline 9.60 & 0.73 & 0.77 & 13.15 & 13.79 & 45.00 & 44.67 & 9.60 \\
\hline 11.25 & 0.94 & 1.00 & 11.97 & 12.55 & 53.00 & 53.12 & 11.25 \\
\hline 12.75 & 1.13 & 1.20 & 11.28 & 11.87 & 61.00 & 60.98 & 12.75 \\
\hline
\end{tabular}

Table 5. Measured forced-jump data for different locations $x_{s}\left(b=0,15 \mathrm{~cm} ; \mathrm{q}=15^{\circ}\right)$

\begin{tabular}{|c|c|c|c|c|c|c|c|}
\hline$x_{s}[\mathrm{~cm}]$ & $\boldsymbol{H}[\mathrm{cm}]$ & $\boldsymbol{Q}_{\boldsymbol{w}}\left[\mathrm{cm}^{3} / \mathrm{s}\right]$ & $\boldsymbol{Q}_{s}\left[\mathrm{~cm}^{3} / \mathrm{s}\right]$ & $\boldsymbol{Q}_{T}\left[\mathrm{~cm}^{3} / \mathrm{s}\right]$ & $y_{1}[\mathrm{~cm}]$ & $y_{2}[\mathrm{~cm}]$ & $L_{j}[\mathrm{~cm}$ \\
\hline \multirow{5}{*}{5} & 45.70 & 500 & 198.30 & 698.30 & 0.29 & 4.80 & 21.00 \\
\hline & 46.98 & 1000 & 168.20 & 1168.20 & 0.50 & 6.40 & 27.00 \\
\hline & 48.05 & 1500 & 141.10 & 1641.10 & 0.75 & 8.90 & 39.00 \\
\hline & 48.98 & 2000 & 188.20 & 2188.20 & 0.97 & 10.80 & 49.00 \\
\hline & 49.85 & 2500 & 202.10 & 2702.10 & 1.18 & 12.70 & 57.00 \\
\hline \multirow{5}{*}{10} & 45.7 & 500 & 173.60 & 673.60 & 0.29 & 4.75 & 19.00 \\
\hline & 46.98 & 1000 & 135.10 & 1135.10 & 0.50 & 6.20 & 26.00 \\
\hline & 48.05 & 1500 & 123.40 & 1623.40 & 0.73 & 8.70 & 36.00 \\
\hline & 48.98 & 2000 & 169.90 & 2169.90 & 0.97 & 10.80 & 46.00 \\
\hline & 49.85 & 2500 & 187.20 & 2687.20 & 1.18 & 12.70 & 57.00 \\
\hline \multirow{5}{*}{15} & 45.7 & 500 & 155.30 & 655.30 & 0.29 & 4.70 & 18.00 \\
\hline & 46.98 & 1000 & 120.30 & 1120.30 & 0.50 & 6.10 & 25.00 \\
\hline & 48.05 & 1500 & 109.50 & 1609.50 & 0.73 & 8.40 & 35.00 \\
\hline & 48.98 & 2000 & 146.30 & 2146.30 & 0.94 & 10.40 & 44.00 \\
\hline & 49.85 & 2500 & 168.40 & 2668.40 & 1.13 & 12.10 & 52.00 \\
\hline \multirow{5}{*}{20} & 45.7 & 500 & 123.20 & 623.20 & 0.29 & 4.80 & 19.00 \\
\hline & 46.98 & 1000 & 102.30 & 1102.30 & 0.50 & 6.30 & 26.00 \\
\hline & 48.05 & 1500 & 92.10 & 1592.10 & 0.73 & 8.60 & 37.00 \\
\hline & 48.98 & 2000 & 129.60 & 2129.60 & 0.94 & 10.70 & 47.00 \\
\hline & 49.85 & 2500 & 144.80 & 2644.80 & 1.13 & 12.20 & 56.00 \\
\hline \multirow{5}{*}{25} & 45.7 & 500 & 111.30 & 611.30 & 0.29 & 4.85 & 20.00 \\
\hline & 46.98 & 1000 & 92.30 & 1092.30 & 0.50 & 6.40 & 27.00 \\
\hline & 48.05 & 1500 & 88.50 & 1588.50 & 0.73 & 8.70 & 38.00 \\
\hline & 48.98 & 2000 & 113.40 & 2113.40 & 0.94 & 10.80 & 48.00 \\
\hline & 49.85 & 2500 & 128.10 & 2628.10 & 1.13 & 12.30 & 57.00 \\
\hline \multirow{5}{*}{30} & 45.7 & 500 & 101.20 & 601.20 & 0.29 & 4.90 & 21.00 \\
\hline & 46.98 & 1000 & 86.30 & 1086.30 & 0.50 & 6.50 & 28.00 \\
\hline & 48.05 & 1500 & 72.50 & 1572.50 & 0.73 & 8.80 & 39.00 \\
\hline & 48.98 & 2000 & 98.20 & 2098.20 & 0.94 & 10.90 & 49.00 \\
\hline & 49.85 & 2500 & 102.50 & 2602.50 & 1.13 & 12.40 & 58.00 \\
\hline
\end{tabular}


Table 6. Calculated forced-jump data for different locations $x_{s}\left(b=0,15 \mathrm{~cm} ; \mathrm{q}=15^{\circ}\right)$

\begin{tabular}{|c|c|c|c|c|c|c|c|c|c|}
\hline$x_{s}[\mathrm{~cm}]$ & $Q_{w} / Q_{s}$ & $y_{2} / y_{1}$ & $L_{f} / y_{1}$ & $v_{1}[\mathrm{~cm} / \mathrm{s}]$ & $\boldsymbol{v}_{2}[\mathrm{~cm} / \mathrm{s}]$ & $v_{s}[\mathrm{~cm} / \mathrm{s}]$ & $F_{1}$ & $F_{2}$ & $E_{L} / y_{1}$ \\
\hline \multirow{5}{*}{5} & 10.63 & 16.55 & 72.41 & 226.86 & 19.14 & 173.95 & 13.45 & 0.279 & 74.26 \\
\hline & 12.37 & 12.80 & 54.00 & 239.23 & 24.02 & 147.54 & 11.88 & 0.303 & 58.21 \\
\hline & 2.88 & 11.87 & 52.00 & 263.16 & 24.26 & 123.77 & 9.70 & 0.260 & 35.80 \\
\hline & 7.402 & 11.13 & 50.52 & 271.30 & 26.66 & 165.09 & 8.79 & 0.259 & 28.17 \\
\hline & 12.16 & 10.76 & 48.31 & 278.77 & 28.00 & 177.28 & 8.19 & 0.251 & 23.47 \\
\hline \multirow{5}{*}{10} & 11.77 & 16.38 & 65.52 & 226.86 & 18.66 & 152.28 & 13.45 & 0.273 & 74.46 \\
\hline & 13.35 & 12.40 & 52.00 & 263.16 & 24.09 & 118.51 & 11.88 & 0.309 & 58.60 \\
\hline & 3.22 & 11.92 & 49.32 & 270.37 & 24.55 & 108.25 & 10.10 & 0.266 & 39.70 \\
\hline & 8.313 & 11.13 & 47.42 & 271.30 & 26.44 & 149.04 & 8.79 & 0.257 & 28.17 \\
\hline & 13.7 & 10.76 & 48.31 & 278.77 & 27.84 & 164.21 & 8.19 & 0.250 & 23.47 \\
\hline \multirow{5}{*}{15} & 13.67 & 16.21 & 62.07 & 226.86 & 18.35 & 136.23 & 13.45 & 0.270 & 74.65 \\
\hline & 14.85 & 12.20 & 50.00 & 263.16 & 24.17 & 105.53 & 11.88 & 0.313 & 58.80 \\
\hline & 4.06 & 11.51 & 47.95 & 270.37 & 25.21 & 96.05 & 10.10 & 0.278 & 40.09 \\
\hline & 9.78 & 11.06 & 46.81 & 279.96 & 27.15 & 128.33 & 9.22 & 0.269 & 32.03 \\
\hline & 16.29 & 10.71 & 46.02 & 291.10 & 29.02 & 147.72 & 8.74 & 0.266 & 28.13 \\
\hline \multirow{5}{*}{20} & 15.43 & 16.55 & 65.52 & 226.86 & 17.08 & 108.07 & 13.45 & 0.249 & 74.39 \\
\hline & 17.27 & 12.60 & 52.00 & 263.16 & 23.02 & 89.74 & 11.88 & 0.293 & 58.45 \\
\hline & 4.49 & 11.78 & 50.68 & 270.37 & 24.36 & 80.79 & 10.10 & 0.265 & 39.84 \\
\hline & 10.83 & 11.38 & 50.00 & 279.96 & 26.19 & 113.68 & 9.22 & 0.256 & 31.74 \\
\hline & 16.95 & 10.80 & 49.56 & 291.10 & 28.52 & 127.02 & 8.74 & 0.261 & 28.06 \\
\hline \multirow{5}{*}{25} & 17.64 & 16.72 & 68.97 & 226.86 & 16.58 & 97.63 & 13.45 & 0.240 & 74.24 \\
\hline & 19.52 & 12.80 & 54.00 & 263.16 & 22.46 & 80.96 & 11.88 & 0.283 & 58.28 \\
\hline & 4.94 & 11.92 & 52.05 & 270.37 & 24.02 & 77.63 & 10.10 & 0.260 & 39.72 \\
\hline & 11.59 & 11.49 & 51.06 & 279.96 & 25.75 & 99.47 & 9.22 & 0.250 & 31.65 \\
\hline & 20.69 & 10.88 & 50.44 & 291.10 & 28.11 & 112.37 & 8.74 & 0.256 & 27.98 \\
\hline \multirow{5}{*}{30} & 20.37 & 16.90 & 72.41 & 226.86 & 16.14 & 88.77 & 13.45 & 0.233 & 74.10 \\
\hline & 24.39 & 13.00 & 56.00 & 263.16 & 21.99 & 75.70 & 11.88 & 0.275 & 58.10 \\
\hline & 10.63 & 12.05 & 53.42 & 270.37 & 23.51 & 63.60 & 10.10 & 0.253 & 39.60 \\
\hline & 12.37 & 11.60 & 52.13 & 279.96 & 25.33 & 86.14 & 9.22 & 0.245 & 31.55 \\
\hline & 2.88 & 10.97 & 51.33 & 291.10 & 27.62 & 89.91 & 8.74 & 0.250 & 27.91 \\
\hline
\end{tabular}

\subsection{Effect of considered parameters on characteristics of forced hydraulic jump}

The hammering of two flows with each other will reduce the velocity of flow and in turn increase the tailwater depth, which pushes the formed jump to move towards the upstream side. In this case the jump is called a forced jump. Consequently, the cross-jet affects the following characteristics of the forced

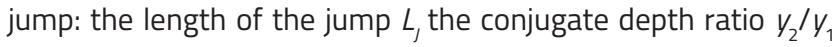
and the energy dissipated along the jump $E_{L}$.

The effect exerted on the forced jump characteristics mainly depends on the direction, location, velocity, and discharge of the cross flow jet, as well as on Froude number $F_{1}$. Therefore, different locations $x_{s^{\prime}}$ angles $\theta$ and widths $b$ of the slot were tested considering the same values of both headwater depth
$H$ and corresponding discharge $Q_{w}$ used before in the case of a free jump.

The effect of the considered parameters on the characteristics of the forced jump will be discussed in the following section, as related to Eqns (19), (20) and (21).

\subsubsection{Effect of slot location $(x)$}

Six values for $x_{s}$ were considered. In this case, both $\theta$ and $b$ were kept constant at $15^{\circ}$ and $0.15 \mathrm{~cm}$, respectively. Measured and calculated data obtained due to variation of slot location are given in Tables 5 and 6, respectively. As illustrated in Tables 5 and 6 , the existence of the cross-jet flow decreases values of $\left(y_{2} / y_{1}\right)$ and $\left(L / y_{1}\right)$, whereas slightly increasing values of $\left(E_{L} / y_{1}\right)$ compared to those obtained for the free jump condition, Tables 
2 and 3. Also, it can be seen that slot location at $x_{s}=15 \mathrm{~cm}$ gives the minimum values of $\left(y_{2} / y_{1}\right)$ and $\left(L / y_{1}\right)$, and maximum values of $\left(E_{L} / y_{1}\right)$, compared to other locations.

A considerable decrease in $L$,value is expressed graphically, as shown in Figure 8 . This result is logical as a high turbulence is introduced by the reversed cross jet to the jump. This turbulence dissipates energy over a shorter length. It was observed from experiments that slot location at the contracted depth or before it results in formation of a splashing jump. In such situation, the formed hydraulic jump disintegrates completely and is composed of a heavy spray formed of various-size water droplets. Such a type of jump must be avoided due to its harmful effect on the channel bed just downstream of the jump.

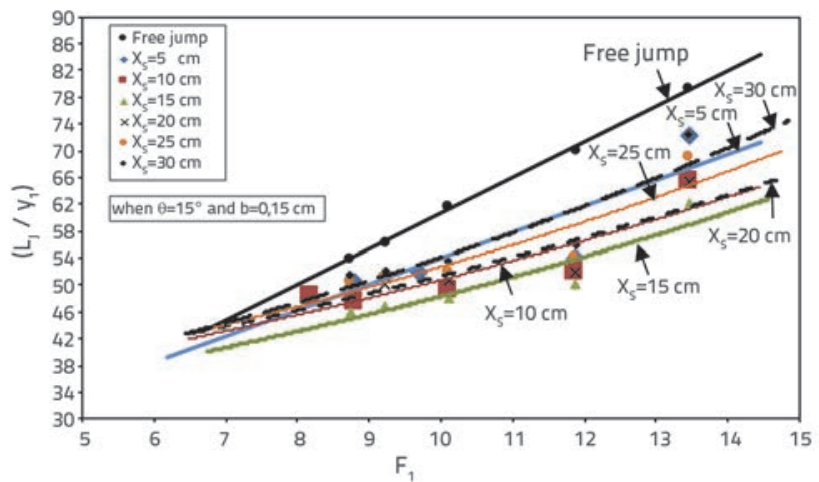

Figure 8. Relation between $\left(L / y_{1}\right)$ and $F_{1}$, with variation of slot location $x_{s}$

\subsubsection{Cross jet direction effect $(\theta)$}

Six slot angle values were tested, i.e. $\theta=15^{\circ}, 30^{\circ}, 45^{\circ}, 60^{\circ}, 75^{\circ}$ i $90^{\circ}$, where slot width $b$ and location $x_{s}$ were kept constant at $0.15 \mathrm{~cm}$ and $15 \mathrm{~cm}$, respectively. Both measured and calculated data were obtained.

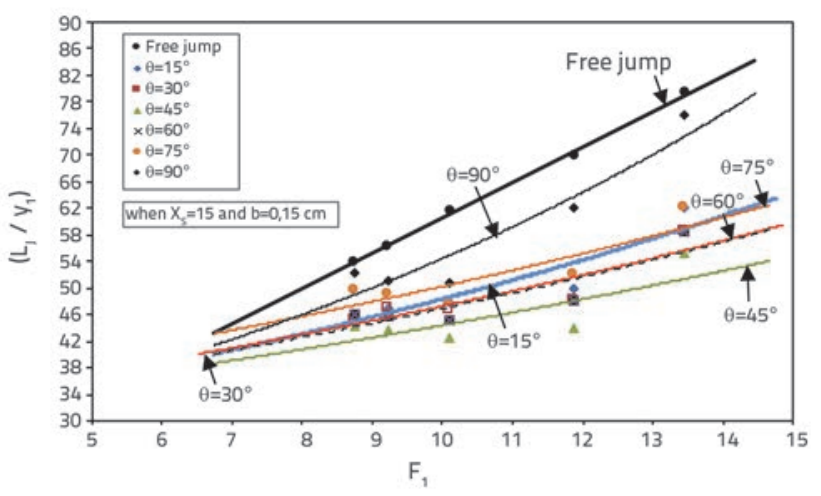

Figure 9. Relation between relative jump length $\left(L_{J} / y_{1}\right)$ and $F_{1}$, with variation of slot angle $\theta$

Both the conjugate depth ratio $\left(y_{2} / y_{1}\right)$ and the relative length of the forced jump $\left(L / y_{1}\right)$, are greatly affected by variation of the slot inclination angle $\theta$. However, there is a poor effect on the relative energy loss $\left(E_{L} / y_{1}\right)$, as shown in Figure 9. The slot inclination angle $\theta=45^{\circ}$ and, to a small extent, $\theta=60^{\circ}$, gives the minimum values of $\left(y_{2} / y_{1}\right)$ and $\left(L / y_{1}\right)$, i.e. the maximum value of the relative energy loss $\left(E_{L} / y_{1}\right)$ compared to the other values of angle $\theta$. It should be noted that, according to Gobran [33], the angle that gives the above minimum and the maximum values is $\theta=60^{\circ}$.

\subsubsection{Effect of slot width (b)}

Four values of slot width $(b)$ were examined, where $b=0.15$, $0.20,0.25$ and $0.30 \mathrm{~cm}$. Both $\left(x_{s}\right)$ and $(\theta)$ were kept constant at $15 \mathrm{~cm}$ and $45^{\circ}$, respectively.

Figure 10 shows great effect on the relative jump length due to variation of slot width. It is clear that there is a significant decrease in the values of $\left(y_{2} / y_{1}\right)$ and $\left(L_{j} / y_{1}\right)$, as compared to those obtained for the free jump condition. In fact, a poor effect on the values of $\left(E_{L} / y_{1}\right)$ is noted, and the best results of those values are recorded when $b=0.30 \mathrm{~cm}$.

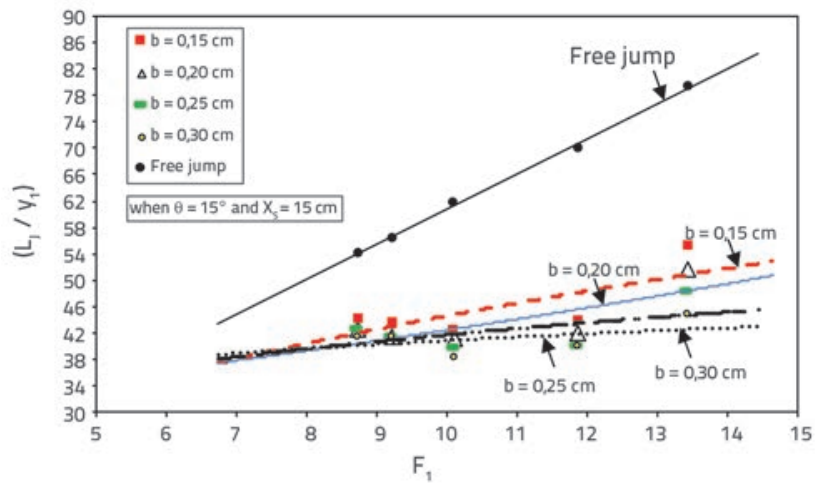

Figure 10. Relation between $\left(L / y_{1}\right)$ and $F_{1}$ due to variation of slot width $b$

\subsubsection{Effect of considered parameters on discharge characteristics of the slot}

According to experimental results listed in Table 6, the discharge of slot $Q_{s}$ is greatly affected by slot characteristics: position $x_{s^{\prime}}$

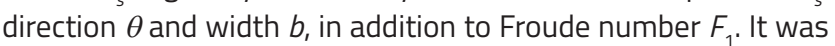
also established that the values of $Q_{W} / Q_{S}$ increase with an increase in the distance of slot location $x_{s^{\prime}}$. This result is logical since the head on the slot, $h_{s}$ decreases as $x_{s}$ increases and, in turn, the slot discharge decreases. The inclination angle of slot $\theta=45^{\circ}$ gives the minimum value of $Q_{w} / Q_{S^{\prime}}$ while $\theta=90^{\circ}$ gives the highest value. An increase in the slot width $b$ results in the decreases of relative discharge $Q_{W} / Q_{S}$. The values of the relative discharge of slot $Q_{w} / Q_{S^{\prime}}$ and the corresponding values of discharge coefficient $C_{d s^{\prime}}$ are given according to the relative values of slot location $x_{s} / y_{1}$, slot width $b / y_{1}$ and direction $\theta_{1}$ as listed in Table 7. 
Table 7. Values of $Q_{w} / Q_{s} \mathrm{i} C_{d s}$ corresponding to relative values of $x_{s} / y_{1}, \theta$ and $b / y_{1}$

\begin{tabular}{|c|c|c|c|c|c|c|c|c|c|}
\hline$F_{1}$ & \multicolumn{3}{|c|}{$\begin{array}{c}b=0.15 \mathrm{~cm}, \theta=15^{\circ} \\
x_{s}=5,10,15,20,25,30 \mathrm{~cm}\end{array}$} & \multicolumn{3}{|c|}{$b=0.15 \mathrm{~cm}, x_{s}=15 \mathrm{~cm}$} & \multicolumn{3}{|c|}{$\begin{array}{c}x_{s}=0.15 \mathrm{~cm}, \theta=15^{\circ} \\
b=5,10,15,20,25,30 \mathrm{~cm}\end{array}$} \\
\hline \multirow{7}{*}{13.45} & $x_{s} / y_{1}$ & $Q_{W} / Q_{S}$ & $C_{d s}$ & $\theta$ & $Q_{w} / Q_{s}$ & $C_{d s}$ & $b / y_{1}$ & $Q_{W} / Q_{S}$ & $C_{d s}$ \\
\hline & 17.24 & 2.52 & 0.58 & 15 & 3.22 & 0.47 & 0.52 & 2.16 & 0.70 \\
\hline & 34.48 & 2.88 & 0.52 & 30 & 2.66 & 0.57 & 0.69 & 1.63 & 0.70 \\
\hline & 51.72 & 3.22 & 0.47 & 45 & 2.16 & 0.7 & 0.86 & 1.37 & 0.67 \\
\hline & 68.97 & 4.06 & 0.38 & 60 & 2.36 & 0.64 & 1.03 & 1.28 & 0.6 \\
\hline & 86.20 & 4.49 & 0.35 & 75 & 2.70 & 0.56 & & & \\
\hline & 103.45 & 4.94 & 0.32 & 90 & 4.56 & 0.33 & & & \\
\hline \multirow{6}{*}{11.88} & 10.00 & 5.95 & 0.48 & 15 & 8.31 & 0.35 & 0.30 & 5.29 & 0.56 \\
\hline & 20.00 & 7.40 & 0.39 & 30 & 6.43 & 0.46 & 0.40 & 3.45 & 0.64 \\
\hline & 30.00 & 8.31 & 0.35 & 45 & 5.29 & 0.56 & 0.50 & 3.30 & 0.64 \\
\hline & 40.00 & 9.78 & 0.31 & 60 & 7.04 & 0.42 & 0.60 & 2.87 & 0.52 \\
\hline & 50.00 & 10.83 & 0.28 & 75 & 8.24 & 0.36 & & & \\
\hline & 60.00 & 11.59 & 0.26 & 90 & 10.68 & 0.28 & & & \\
\hline \multirow{6}{*}{10.10} & 6.67 & 10.63 & 0.40 & 15 & 13.70 & 0.32 & 0.205 & 9.01 & 0.48 \\
\hline & 13.70 & 12.16 & 0.35 & 30 & 10.84 & 0.4 & 0.274 & 5.53 & 0.59 \\
\hline & 20.55 & 13.70 & 0.32 & 45 & 9.01 & 0.48 & 0.342 & 5.18 & 0.51 \\
\hline & 27.40 & 16.29 & 0.27 & 60 & 13.46 & 0.32 & 0.411 & 4.70 & 0.46 \\
\hline & 34.25 & 16.95 & 0.26 & 75 & 16.72 & 0.26 & & & \\
\hline & 41.10 & 20.69 & 0.22 & 90 & 18.27 & 0.24 & & & \\
\hline \multirow{6}{*}{9.22} & 5.15 & 10.63 & 0.53 & 15 & 13.67 & 0.42 & 0.160 & 9.10 & 0.63 \\
\hline & 10.31 & 11.77 & 0.48 & 30 & 11.14 & 0.51 & 0.213 & 6.64 & 0.65 \\
\hline & 15.96 & 13.67 & 0.42 & 45 & 9.10 & 0.63 & 0.266 & 6.09 & 0.56 \\
\hline & 21.28 & 15.43 & 0.37 & 60 & 11.22 & 0.51 & 0.319 & 5.29 & 0.54 \\
\hline & 26.60 & 17.64 & 0.33 & 75 & 16.72 & 0.34 & & & \\
\hline & 31.92 & 20.37 & 0.29 & 90 & 18.30 & 0.31 & & & \\
\hline \multirow{6}{*}{8.74} & 4.24 & 12.37 & 0.56 & 15 & 14.85 & 0.47 & 0.133 & 10.63 & 0.66 \\
\hline & 8.48 & 13.35 & 0.52 & 30 & 13.30 & 0.53 & 0.177 & 7.44 & 0.71 \\
\hline & 13.27 & 14.85 & 0.47 & 45 & 10.63 & 0.66 & 0.221 & 6.48 & 0.65 \\
\hline & 17.70 & 17.27 & 0.41 & 60 & 11.42 & 0.62 & 0.265 & 6.06 & 0.58 \\
\hline & 22.12 & 19.52 & 0.37 & 75 & 13.21 & 0.53 & & & \\
\hline & 26.55 & 24.39 & 0.30 & 90 & 20.59 & 0.34 & & & \\
\hline
\end{tabular}

\section{Results and discussion}

Considering the best location $x_{5}=15 \mathrm{~cm}$, the angle $\theta=45^{\circ}$ and the width of the slot $b=30 \mathrm{~cm}$, the percentage decrease in values of the conjugate depths, the relative jump length, and the percentage increase of energy loss compared to those values obtained for free jump, i.e. $\Delta\left(y_{2} / y_{1}\right) \%, \Delta\left(L / y_{1}\right) \%$ and $\Delta E_{L} \%$, were obtained and listed as shown in Table 8, where

$\Delta\left(y_{2} / y_{1}\right) \%=\frac{\left(y_{2} / y_{1}\right)_{0}-\left(y_{2} / y_{1}\right)}{\left(y_{2} / y_{1}\right)_{0}} \times 100$
Here, $\left(y_{2} / y_{1}\right)_{0}$ is the conjugate depth in case of a free jump. The situation is similar for the relative length and the energy loss.

The maximum value of $\Delta\left(y_{2} / y_{1}\right) \%$ equals $22.70 \%$ when $F_{1}$ $=11.88$, while the maximum value of $\left(L / y_{1}\right)$ is about $43.50 \%$ when $F_{1}=13.45$. As for the energy loss, the results show that the maximum value of $\Delta E_{L}$ is about $5 \%$ when $F_{1}=10.10$.

To analyse the shape of jump with respect to slot width $b$, four experiments were carried out using different values of slot width $b$, i.e. $\mathrm{b}=0.15,0.20,0.25$ and $0.30 \mathrm{~cm}$. Other parameters were kept constant: $x_{s}=15 \mathrm{~cm}, \theta=45^{\circ}$ and $F_{1}=10.10$. Figure 
Table 8. Percentage decrease in $\left(y_{2} / y_{1}\right),\left(L / y_{1}\right)$ and percentage increase in $E_{L}$ compared to the case of free jump

\begin{tabular}{|c|c|c|c|c|c|c|c|c|c|}
\hline$F_{1}$ & $\left(y_{2} / y_{1}\right)_{0}$ & $\left(y_{2} / y_{1}\right)$ & $\Delta\left(y_{2} / y_{1}\right)[\%]$ & $\left(L_{J} / y_{1}\right)_{0}$ & $\left(L_{J} / y_{1}\right)$ & $\Delta\left(L_{j} / y_{1}\right)[\%]$ & $E_{L}$ & $E_{L}$ & $\Delta E_{L}[\%]$ \\
\hline 13.45 & 17.24 & 15.34 & 11.02 & 79.31 & 44.83 & 43.47 & 21.4 & 21.7 & 1.35 \\
\hline 11.88 & 15.00 & 11.60 & 22.70 & 70.00 & 40.00 & 42.86 & 28.1 & 29.5 & 4.90 \\
\hline 10.10 & 13.15 & 10.75 & 18.25 & 61.64 & 38.36 & 37.77 & 28.2 & 29.7 & 5.32 \\
\hline 9.22 & 11.97 & 10.74 & 10.28 & 56.38 & 41.49 & 26.41 & 29.4 & 30.3 & 3.20 \\
\hline 8.74 & 11.28 & 10.40 & 7.80 & 53.98 & 41.59 & 22.95 & 31.2 & 32.0 & 2.56 \\
\hline
\end{tabular}
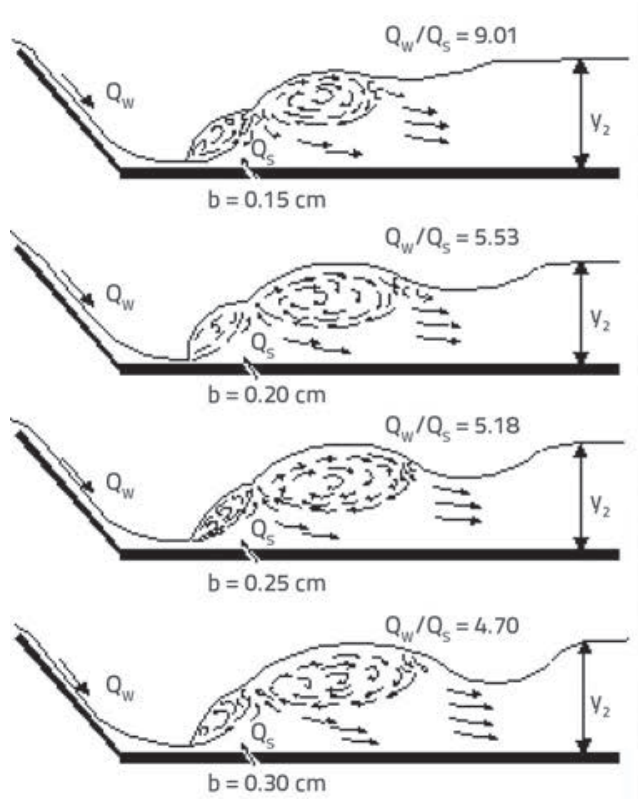

Figure 11. Effect of slot width increase on jump shape

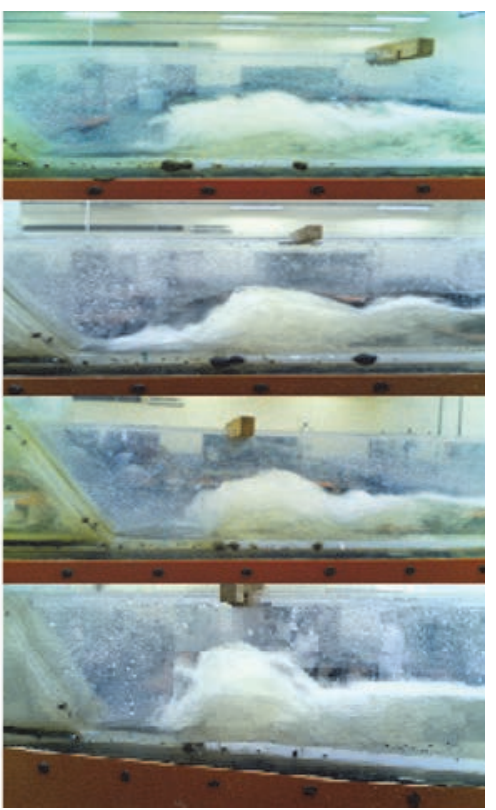

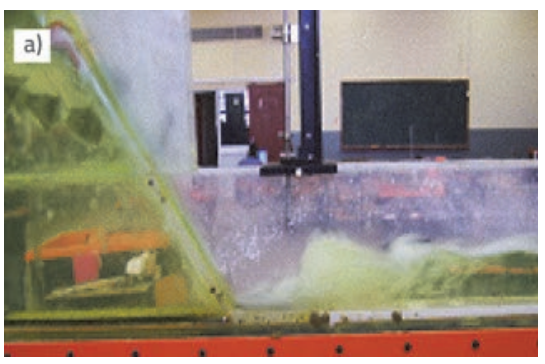

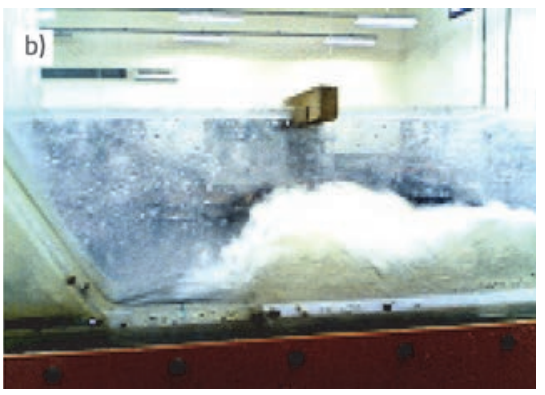

Figure 13. Occurrence of: a) splashing jump, b) overhead jump
11 shows the sequence of jump formation as a result of an increase in slot width $b$. It is clear from this figure that the length of jump decreases as the slot width increases, but with a decreasing rate, compared to the case of free jump. This is the reason why the increase in maximum values of $\Delta\left(y_{2} / y_{1}\right) \%$ and $\Delta\left(L / y_{1}\right) \%$ does not match the increase in slot width $b$.

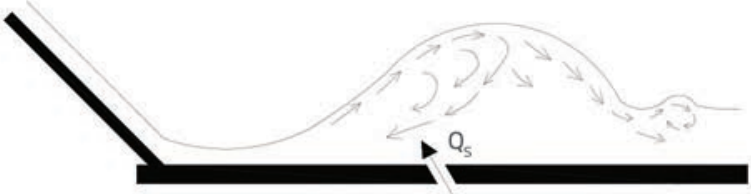

b $>0.30 \mathrm{~cm}$

Figure 12. Shape of overhead jump due to increase in slot width

It can be noted from the experiments that, when the width of slot is greater than the range considered in the present study, an overhead jump occurs and falls away with a length bigger than the length of the free jump, as shown in Figure 12. In this case, the flow issuing from the slot is strong as the jump is lifted to a high head and then falls down at a distance from the contracted section that is usually longer than the length of the free jump. In this case, the falling flow at the end of the jump produces high velocities near the channel bed, causing excessive dangerous eddies.

Experiments show that concentration of the cross jet at the contracted section or before it creates a splashing jump, as shown in Figure 13.a. On the other hand, the effect on jump characteristics is negligible when the cross jet is located behind the jump end. It can also be noted that an overhead jump is produced if the slot width is increased beyond the tested values, as shown in Figure 13b. This phenomenon occurs because an increase in slot width causes increase in jet discharge, which in turn increases horizontal component of jet momentum, acting against the main flow. Thus the momentum resulting from the two flows is directed upward causing an overhead jump that increases the length of jump, compared to the length obtained for smaller widths.

\section{Conclusion}

A comprehensive analytical and experimental study was conducted to analyse the cross-jet flow when used to dissipate the energy of flow falling over an ogee weir spillway. The obtained 
results show that the hydraulic jump, formed downstream of an ogee weir spillway, can be controlled using a reversed cross jet dissipator. The suggested cross jet dissipator can be used to convert the repelled hydraulic jump not only to a perfect jump, but also to a drowned jump, hence greatly reducing the length of the required solid floor. The results obtained, together with the developed formula (15), can be used to predict the loss of energy for a hydraulic jump controlled by reversed cross jet. The following conclusions are drawn based on the analysis and discussion of experimental results obtained in the present study:

- The increase in Froude number of falling flow $F_{1}$ results in an increase in the conjugate depth ratio and the relative length of jump, i.e. in the decrease in relative discharge of cross jet $Q_{w} / Q_{S}$ ).

- Minimum values of both the conjugate depth ratio and jump length, and maximum values of energy loss, are obtained if the cross jet flow is located within the length of the forced perfect jump, as close as possible to the contracted section.

- Minimum values of both the conjugate depth ratio and jump length, and maximum values of energy loss, are obtained in case the cross jet is located at an inclination angle $\theta=45^{\circ}$.

- An increase in slot width results in a decrease in the conjugate depth ratio, a decrease in the jump length, and a slight increase in energy loss. The jet width value should not exceed the contracted depth value as otherwise an overhead jump will occur.
- Relative discharge of cross jet $\left(Q_{W} / Q_{S}\right)$ decreases when:

- the jet is located just behind the contracted depth

- the inclination angle of jet is $\theta=45^{\circ}$

- the width of the jet is increased, and (iv) values of Froude number $F_{1}$ are high.

- A numerical example is applied and some relationships and theoretically derived equations are used. The obtained results reveal that the cross jet flow shortens the length of the solid floor required for repelled jump by $79 \%$, while the reduction in the jump length itself amounts to $19 \%$.

- The cross jet flow results in a slight increase in energy loss, amounting to approximately $5 \%$ when $\theta=45^{\circ}$.

- The cross jet flow gives a decrease in the conjugate depth ratio of up to $23 \%$ of its original ratio.

All points relating to the presented issue can not be covered in a single paper. Therefore, it is recommended to extend the study of the problem to include the following items:

- Behaviour of hydraulic jump with tailwater depth lower than the second conjugated depth.

- State of submerged hydraulic jump.

- Further detailed investigation of the presented problem using a large scale model.

- The effect of cross jet flow location on the inclined surface itself.

\section{Appendix 1: The general layout of the experimental set-up}

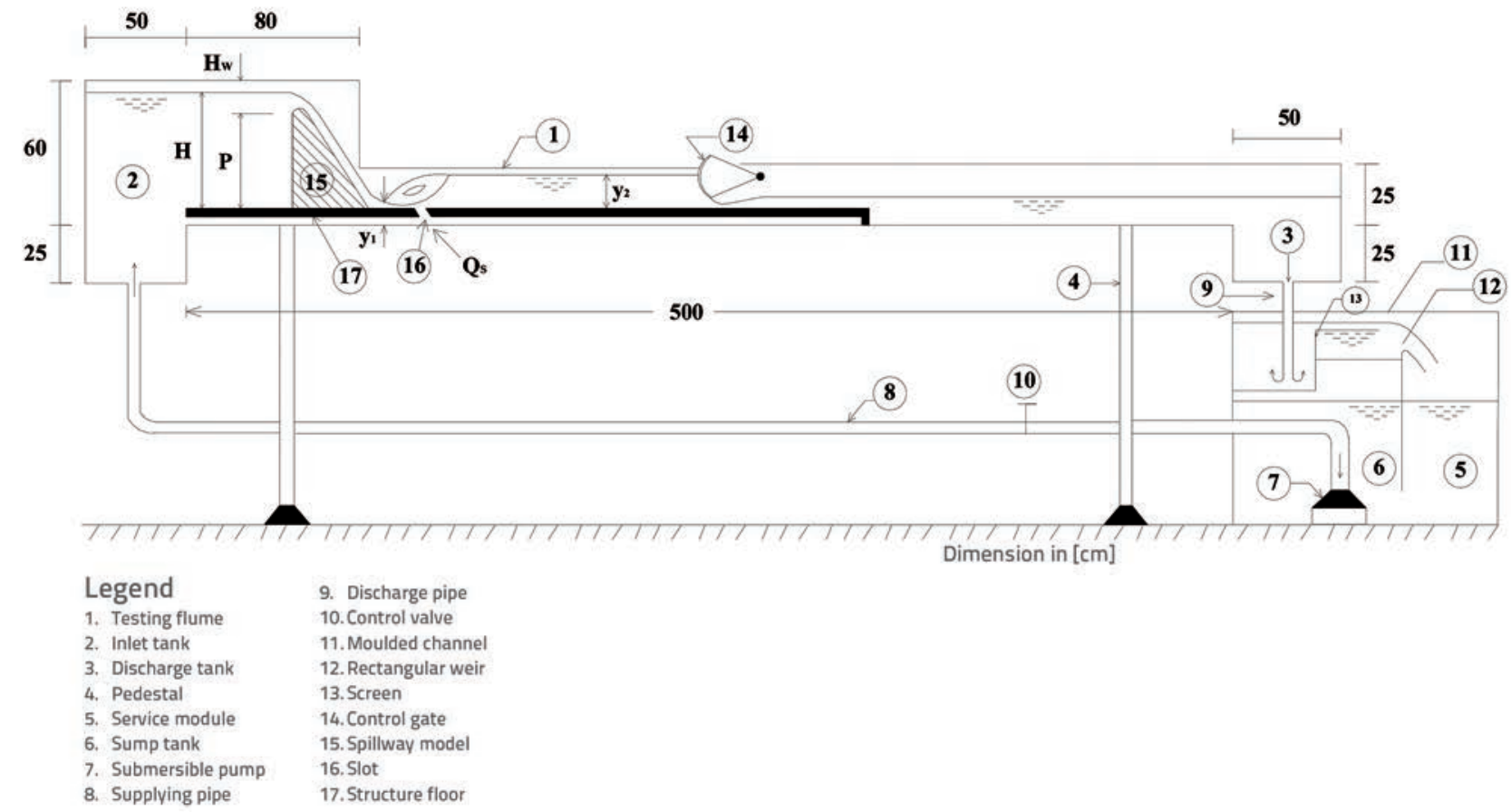




\section{REFERENCES}

[1] Hager, W.: Scour in Hydraulic Engineering, Proceedings of the ICE - Water Management, 3 (2007), pp.159-168, https://doi. org/10.1680/wama.2007.160.3.159

[2] Simon, A., Korom, S., Hydraulics, Prentice-Hill, Inc, New Jersey, 1997.

[3] Novak, P., Moffat, A.I.B., Nalluri, C., Narayanan, R.: Hydraulic Structures, Spon Press, London, 2001 \& 2006.

[4] Manoochehr, F., Sadegh, H., Babak, L., Peyman, A.: Reduction of Stilling Basin Length with Tall End Sill, Journal of Hydrodynamics, 4 (2011), pp. 498-502.

[5] Verma, D.: Stilling Basins for Pipe Outlets Using Wedge-shaped Splitter Block, Journal of Irrigation and Drainage Engineering, 3 (2000), pp. 179-184, https://doi.org/10.1061/(ASCE)07339437(2000)126:3(179)

[6] Barani, G.A., Rahnama, M.B., Sohrabipoor, N.: Investigation of Flow Energy Dissipation Over Different Stepped Spillways, American Journal of Applied Sciences, 6 (2005), pp. 1101-1105.

[7] Chafi, C., Abdelkrim, H., Seddini, A.: Study of Flow and Energy Dissipation in Stepped Spillway, Jordan Journal of Civil Engineering, 1 (2010), pp. 1-11.

[8] Komora, Y.: Spillway Design Using Jet Collision for Energy Dissipation. Power Technology and Engineering (formerly Hydrotechnical Construction), 4 (1969), pp. 363-364, https://doi. org/10.1007/BF02378164

[9] Vollmer, E., Khader, M. H.: Counter Current Energy Dissipator for Conduit Outlets, International Journal of Water \& Power, 7 (1971), pp. 260-263.

[10] Kao, T. Y.: Hydraulic Jump Assisted by Cross jet. Proc., ASCE., J. Hydraulic Division, HY, 12 (1971), pp. 2037-2050.

[11] Novak, P., Cabelka, J.: Modes in Hydraulic Engineering: Physical Principles and Design Applications, Pitman, London, 1981.

[12] Vischer, D., Hager, W.: Dam Hydraulics, John Wiley \& Sons, Ltd, Chichester, 1998.

[13] Frizell, K., Renna, F., Matos, J.: Cavitation Potential of Flow on Stepped Spillways. J. Hydraulic Engineering, 6 (2013), pp. 630636, https://doi.org/10.1061/(ASCE)HY.1943-7900.0000715

[14] Chanson, C.: The hydraulics of Open Channel Flow, Elsevier Butterworth-Heinemann: Oxford, 2004.

[15] O'Hern, T.J.:Cavitation Inception Scale Effects: I. Nuclei distributions in natural waters. II. Cavitation inception in a turbulent shear flow, Ph.D. thesis, California Inst. of Technology, Pasadena, 1987.

[16] Baur, T., Köngeter, J.: The three-dimensional Character of Cavitation Structures in A turbulent Shear Layer, $19^{\text {th }}$ IAHR International Symposium on Hydraulic Machinery and Cavitation, Environmental Engineering Society of Singapore, Singapore, 1998.
[17] Iyer, C.O., Ceccio, S.L.: The influence of Developed Cavitation on The flow of A turbulent Shear Layer, Phys. Fluids, 10 (2002), pp. 3413-3431, https://doi.org/10.1063/1.1501541

[18] Pfister, M., Hager, W., Minor, H.: Stepped Chutes: Pre-aeration and Spray Reduction, Inter. J. of Multiphase Flow, 2 (2005), pp. 269284.

[19] Pfister, M., Hager, W., Minor H.: Bottom Aeration of Stepped Spillways, J. Hydraulic Engineering, 8 (2006), pp. 850-853, https:// doi.org/10.1061/(ASCE)0733-9429(2006)132:8(850)

[20] Boes, R., Hager, W.: Two-Phase Flow Characteristics of Stepped Spillways, J. Hydraulic Engineering, 9 (2003), pp. 661-670, https:// doi.org/10.1061/(ASCE)0733-9429(2003)129:9(661)

[21] Amador, A., Sánchez-Juny, M., Dolz, J.: Developing Flow Region and Pressure Fluctuations on Steeply sloping Stepped spillways, J. Hydraulic. Engineering, 12 (2009), pp. 1092-1100, https://doi. org/10.1061/(ASCE)HY.1943-7900.0000118

[22] Crummett, W., Western, A.: University Physics: Models and Applications, WCB/McGraw-Hill: USA, 1994.

[23] Balakin, B., Hoffmann, A.C., Kosinski, P.: The collision efficiency in a shear flow, Chemical engineering science, 1 (2012), pp. 305-312, https://doi.org/10.1016/j.ces.2011.09.042

[24] Abourohim, M.: Characteristics of Flow Over Ungated Ogee Weir Spillway, Alexandria Engineering J., July 30, 1991.

[25] Stephenson, D.: Energy Dissipation Down Stepped Spillways, Water power \& Dam construction, 9 (1991), pp. 27-30.

[26] Christodoulou, G.: Energy Dissipation of Stepped Spillways, J. Hydraulic Engineering, 5 (1993), pp. 664-650, https:/doi. org/10.1061/(ASCE)0733-9429(1993)119:5(644)

[27] Chanson, H.: Comparison of Energy Dissipation Between Nappe and Skimming Flow Regimes on Stepped Chutes, J. Hydraulic Research, ASCE, 2 (1994) a, pp. 213-218.

[28] Chamani, M., Rajaratnam, N.: Onset of Skimming Flow on Stepped Spillways, J. Hydraulic Engineering, 9 (1999) b, pp. 969-971.

[29] Rajaratnam, N., Chamani, M.: Energy Loss at Drop, ASCE., J. Hydraulic Research, 3 (1995), pp. 373-384, https:/doi. org/10.1080/00221689509498578

[30] USBR Hydraulic Design of Stilling Basins and Energy Dissipators, Engineering Monograph No.25.

[31] Rajaratnam, N.: Turbulent jets, Elsevier Science, Amsterdam, 1976.

[32] Hager, W., Bremen, R.: Classical Hydraulic jump; sequent depths. J. Hydraulic Research, 5 (1989), pp. 565-585, https://doi. org/10.1080/00221688909499111

[33] Gobran, A.: Effect of Artificially Roughened Bed on The Characteristics of The Hydraulic Jump in Two Dimensional Flow, M. Sc. Thesis, Alexandria university, Alexandria, Egypt, 1982. 